\title{
Prospective analysis of the medicine possession ratio of antidepressants in the private health sector of South Africa, 2006 - 2011
}

\author{
F N Slabbert, ${ }^{1} \mathrm{MSc}$, B H Harvey, ${ }^{2} \mathrm{PhD}, \mathbf{C}$ B Brink, ${ }^{3} \mathrm{PhD}$, M S Lubbe, ${ }^{1} \mathrm{PhD}$ \\ ${ }^{1}$ Medicine Usage in South Africa (MUSA), School of Pharmacy, Faculty of Health Sciences, North-West University, Potchefstroom, \\ North West, South Africa \\ ${ }^{2}$ Centre of Excellence for Pharmaceutical Sciences, School of Pharmacy, Faculty of Health Sciences, North-West University, Potchefstroom, \\ North West, South Africa \\ ${ }^{3}$ Division of Pharmacology, School of Pharmacy, Faculty of Health Sciences, North-West University, Potchefstroom, North West, South Africa
}

Corresponding author: MS Lubbe (martie.lubbe@nwu.ac.za)

Background. Major depressive disorder (MDD) is a disabling mental illness with high morbidity and mortality rates. Inadequate treatment efficacy, unfavourable side-effect profiles and consequent shortfalls in compliance are major stumbling blocks in its treatment. Noncompliance data in low- to middle-income countries are lacking.

Objective. To investigate the prevalence of antidepressant $(\mathrm{AD})$ non-compliance in the private healthcare sector of South Africa (SA).

Methods. We conducted a prospective cohort study analysing AD medicine claims ( $N=35$ 175) for 14135 patients, obtained from a nationally representative pharmaceutical benefit management company, over a 6-year study period (1 January 2006 - 31 December 2011). The medicine possession ratio (MPR) was used as a proxy to determine compliance with AD medication. Only patients $>18$ years of age whose treatment had been initiated by a psychiatrist following an appropriate International Classification of Diseases (10th edition) (ICD10) diagnosis of a mood disorder were included. A patient was considered compliant if the MPR was between $\geq 80 \%$ and $\leq 110 \%$ over a $>4$-month treatment period.

Results. After the first 4 months, only $34 \%$ of patients were compliant. A statistically significant association was found between active ingredient consumed and compliance $(p<0.0001)$. Only $26.2 \%$ of patients who received amitriptyline-containing products were compliant, compared with $38.8 \%$ and $38.7 \%$ for venlafaxine and duloxetine, respectively.

Conclusion. Compliance data collected from pharmacy claims provide a workable estimate of the broader clinical scenario they represent. Although differences between classes of $\mathrm{AD}$ were evident, non-compliance was found to be high in the private healthcare environment of SA, comparable with global trends.

S Afr Med J 2015;105(2):139-144. DOI:10.7196/SAMJ.8394

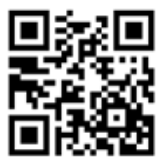

Major depressive disorder (MDD) is a disabling illness affecting people worldwide. The lifetime prevalence for major depression in South Africa (SA) is $9.8 \%,{ }^{[1]}$ as opposed to $16.7 \%{ }^{[2]}$ and $\sim 13 \%$ for the USA and Europe, respectively. ${ }^{[3]}$ MDD not only decreases general health but impairs quality of life, performance at work and at school, and everyday social interactions. MDD poses a substantial risk for suicide, ${ }^{[4]}$ with an estimated $15-20 \%$ mortality rate. ${ }^{[4]}$ The economic impact of affective disorders in Europe (major depression and bipolar depression) amounts to EUR106 billion (2004 figures). ${ }^{[5]}$ Of this amount, nearly EUR29 billion was spent on direct healthcare costs such as hospitalisation, visits to doctors and drug treatment, whereas EUR77 billion was attributable to indirect costs including premature death, sick leave and workdays lost. ${ }^{[5]}$ The economic cost of depressive disorders in the USA in 2007 was estimated to be over USD83 billion, ${ }^{[6]}$ with direct and indirect costs on health expenditure of USD26 billion and 57 billion, respectively. Projections done in 2011 indicated that the total annual cost to South Africans living with severe depression and anxiety disorders amounted to USD3.6 billion. ${ }^{[7]}$ These estimates suggest either that mental illness has a major economic impact, through the effect of disability and stigma on earnings, or that people in lower income groups are at increased risk of mental illness.

The management of MDD is severely compromised by noncompliance.$^{[8]}$ It is recommended that treatment of depression continue for at least 4 - 6 months from the time of remission, to prevent relapse. ${ }^{[9,10]}$ This is extended in high-risk patients, those with recurrent illness and/or those with a history of treatment resistance. Several studies have shown that remission rates for compliant patients with depression are higher than for non-compliant patients, ${ }^{[11,12]}$ and furthermore that sustained antidepressant (AD) use over 12 - 36 months may decrease the risk of relapse further by up to $70 \%$ compared with non-compliant patients. ${ }^{[13]}$ In a Spanish study, 56\% of patients discontinued their $\mathrm{AD}$ treatment within the first 4 months, whereas only $22 \%$ maintained satisfactory adherence over a 5 -year period. ${ }^{[14]}$ Many studies concur that between $30 \%$ and $60 \%$ of patients do not comply with $\mathrm{AD}$ treatment, ${ }^{[15-16]}$ and that up to $30 \%$ are likely to stop taking ADs within the first month after the start of treatment. In addition, $45-60 \%$ of patients will have stopped their prescribed treatment by the end of the third month. ${ }^{[17-19]}$ Without adequate treatment, patients may experience further relapses of depressive episodes. ${ }^{[20]}$ Furthermore, preclinical studies demonstrate that premature discontinuation may evoke a specific sequence of neurobiological events that underlie relapse and treatment resistance. ${ }^{[21,22]}$ Compliance and persistence are therefore key concerns in the pharmacological management of MDD.

No studies have investigated AD compliance in low- to middleincome countries. We therefore studied the prevalence of noncompliance with $\mathrm{AD}$ treatment in the private healthcare sector in SA, using the medicine possession ratio (MPR) as a proxy for 
patient compliance with $\mathrm{ADs}$, and also looking at possible changes in the prescribed daily dosage (PDD) between compliant and non-compliant patients, and whether class of $\mathrm{AD}$ is an additional determinant.

\section{Methods}

We conducted a prospective, descriptive cohort study analysing nationally representative medicine claims data submitted to a privately owned SA pharmaceutical benefit management (PBM) company. The database included all prescriptions for an $\mathrm{AD}$ (Monthly Index of Medical Specialities classification 1.4 ${ }^{[23]}$ for 407586 patients over a 6-year study period, 1 January 2006 - 31 December 2011.

We extracted data for patient demographics (gender and date of birth) and pertinent prescription information (such as drug trade name, days supplied, dispensing date, quantity of medicine prescribed, initial dose, final dose and ICD-10 code per claim). The quality of data was ascertained by several automated validation processes that were applied by the PBM company. There were no missing data fields in the data sets. The variables 'birth date' and 'dispensing date' were used to calculate the age of patients on the date of treatment and the number of days between refills.

A study population was selected according to the inclusion criteria illustrated in Fig. 1. The ICD-10 codes are based on the International Statistical Classification of Diseases and Related Health Problems, 10th edition, published by the World Health Organization. ${ }^{[24]}$ In this study the ICD-10 codes F32 (depressive episode) and F33 (recurrent depressive disorder) were used to identify patients with MDD as diagnosed by a psychiatrist. Thereby it was ensured that data were excluded where ADs may have been used for other illnesses, such as amitriptyline for the treatment of chronic pain. The study population was older than 18 years and consisted of a total of 14135 patients receiving $35175 \mathrm{AD}$ medicine items dispensed on more than two occasions.

The MPR is a well-established method of calculating drug compliance in pharmcoepidemiological studies, including chronic diseases such as depression, ${ }^{[14]}$ hypertension ${ }^{[25]}$ osteoporosis ${ }^{[26}$ and schizophrenia. ${ }^{[27]}$ However, it is important to note that the compliance value obtained from the MPR only gives an indication of the possession of medicine by the patient, and that appropriate consumption of medicine is assumed to ensue from possession. The use of medicine claims data in MPR calculations is helpful in that this information is acceptably accurate, convenient, objective, non-invasive and relatively inexpensive to obtain when a large study population is needed. It is therefore suitable for the calculation of the MPR as an indication of patient compliance with medication therapy.

The MPR is defined as the total number of days for which medication is supplied (medicine treatment period), divided by the number of days in the refill interval, multiplied by $100 .{ }^{[28,29]}$ The MPR is considered acceptable if the calculated value is $\geq 80 \%$ but $\leq 110 \%{ }^{[14]}$ An
MPR of $<80 \%$ indicates the presence of refill gaps, so that possession is considered unacceptably low (undersupply), whereas an MPR $>110 \%$ is considered unacceptably high (oversupply).

Data management and analysis were performed using SAS Version 9.1.3 (SAS Institute, USA). All statistical significance was considered with a probability of $p<0.05$. The practical significance of the results was computed when the $p$-value was statistically significant $(p \leq 0.05)$.

For the purpose of the study, the MPR and the medicine treatment period were used to determine $\mathrm{AD}$ compliance of patients. In order to treat MDD effectively and prevent relapse, patients must be on chronic treatment for at least 120 days. ${ }^{[9,10,28]}$ All patients with an MPR of $<80 \%$ or $>110 \%$ and/or an $\mathrm{AD}$ treatment period of $<120$ days were therefore deemed non-compliant. Conversely, a patient was considered compliant with his/her AD treatment if the MPR was between $\geq 80 \%$ and $\leq 110 \%$, and the $\mathrm{AD}$ treatment period was $>120$ days.

Variables (age, age groups, gender, treatment period and active ingredients) were expressed using descriptive statistics such as frequencies $(n)$, percentages (\%), means, standard deviations (SDs) and $95 \%$ confidence intervals (CIs). Patient age was determined at time of first dispensing and divided into three groups: 18 - 40 years, 41 - 60 years and $\geq 61$ years. Treatment duration was calculated as the time (in days) from the first prescription of the ADs until the last. It was divided into three groups: $\leq 30$ days, between $\geq 31$ days and $\leq 120$ days, and $>120$ days.

The $\chi^{2}$ test was used to determine whether an association existed between proportions of two or more groups (age groups v. MPR groups). Cramer's V statistics were used to test the practical significance of this association. The two-sample $t$-test allowed us to compare the mean MPR of male and female patients. One-way analysis of variance was used to test differences between three or more means and to calculate differences in the adjusted PDD changes between compliant and non-compliant patients. It was operationalised with the general linear model procedure of the SAS Version 9.1.3 system. If a difference was indicated, a Tukey multiple comparison test was performed to determine which groups most significantly influenced the overall difference between groups. Cohen's $d$ was used to evaluate effect size between means (with $d \geq 0.8$ defined as practically significant). ${ }^{[30]}$

The PDD (in $\mathrm{mg}$ ) of an $\mathrm{AD}$ was calculated by multiplying the number of tablets (or volume of suspension or syrup) dispensed during the treatment period and the strength per tablet (or per $\mathrm{mL}$ ), divided by the number of days supplied. Possible PDD changes from the first until the last prescription on the database were determined. The correlation coefficient, $r$, indicated a negative association between the initial PDD and change in PDD $(r<-0.5 ; p=0.0001)$. Possible PDD changes were therefore adjusted for variations in initial dosage.

The study was approved by the Ethics Committee of North-West University, Potchefstroom Campus, North West Province, SA (NWU0046-08-A5), and the boards of directors of the PBM. Data were analysed anonymously.

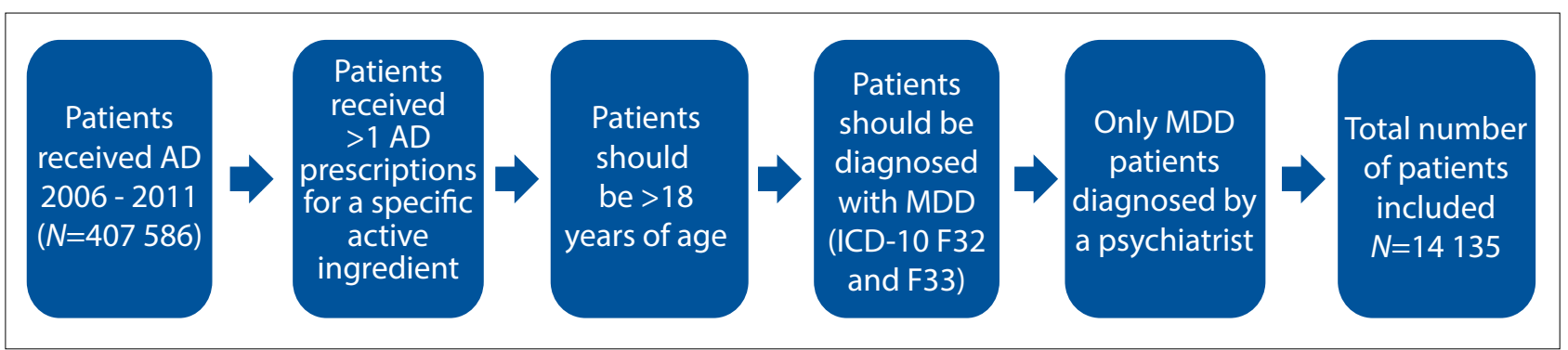

Fig. 1. The inclusion criteria used in the study. 


\section{Results}

\section{MPRs of ADs}

The mean (SD) age of the patients was 50.4 (15.9) years, $71.1 \%$ were women, and $71.1 \%$ received $\mathrm{AD}$ medication for $>4$ months (Table 1). The mean MPR of the 35175 ADs was 98.2\% (95\% CI 96.6 - 99.9) (Table 2). Only $49.6 \%$ of dispensed ADs were associated with an acceptable MPR of between $80 \%$ and $110 \%$ (Table 1).

No statistically significant differences were found between the MPRs of male and female patients: $98.4 \%$ (95\% CI 95.4 - 101.4) v. 98.2\% (95\% CI 96.2 - 100.1) (Table 2). Patients older than 60 years had a lower MPR than those aged 18 - 40 years $(p=0.0169)$ (Table 2$)$.

Table 2 clearly indicates that the treatment period had a statistical $(p=0.0001)$ and practically significant $(d>0.8)$ influence on the MPR of ADs. An abnormally large number of patients were noted to be on treatment for $<30$ days (255.4\%; 95\% CI 235.7 - 275.1). This increase in MPR was also practically significant compared with patients on therapy for between 30 and 120 days (94.1\%; 95\% CI 93.3 - 94.9) and those on therapy for $>120$ days $(81.1 \%$; $95 \%$ CI 80.7 - 81.5) $(d>1.0)$

\section{Patient compliance with AD therapy}

Only $34 \%$ of patients were compliant with the $\mathrm{AD}$ treatment. In the majority of cases (66\%), the MPRs were not in the acceptable range $(80-110 \%)$ and the treatment period was $<120$ days (Table 3 ); these patients were therefore deemed non-compliant.

No statistically significant association was found between gender and patient compliance $(p=0.1342)$. Of practical significance $(p<0.0001$; Cramer V=0.0734), the results reveal that a larger percentage (38.9\%) of patients aged $>60$ years receiving ADs, and who were likely to have chronic comorbidities such as hypertension or diabetes, were compliant compared with those in the 18 - 40 years age group (Table 3 ).

The ten most dispensed AD medications represented $86.1 \%$ of all those dispensed during the study period (Table 1). These include venlafaxine, escitalopram, duloxetine, mirtazapine, citalopram, fluoxetine, bupropion, sertraline, amitriptyline and trazodone. A statistically significant association was found between the type of active ingredients consumed and compliance $(p<0.0001)$ (Table 3 ). Only $26.2 \%$ of patients who received amitriptyline-containing products were compliant compared with $38.8 \%$ and $38.7 \%$ in the case of the ADs with the highest compliance, viz. venlafaxine and duloxetine, respectively (Table 3).

Table 1. Patient demographics and medicine use data

\begin{tabular}{|c|c|}
\hline Age (years), mean (SD) & $50.4(15.9)$ \\
\hline \multicolumn{2}{|c|}{ Age groups (years), $n$ (\% of 14135 ) } \\
\hline$>18-\leq 40$ & $3449(24.4)$ \\
\hline$>40-\leq 60$ & $6537(46.2)$ \\
\hline$>60$ & $4149(29.4)$ \\
\hline \multicolumn{2}{|l|}{ Gender, $n$ (\% of 14135 ) } \\
\hline Female & $10003(70.8)$ \\
\hline Male & $4132(29.2)$ \\
\hline \multicolumn{2}{|c|}{ Treatment period (days), $n$ (\% of 14135 ) } \\
\hline$\leq 30$ & $830(5.9)$ \\
\hline$>30-\leq 120$ & $3256(23.0)$ \\
\hline$>120$ & $10049(71.1)$ \\
\hline \multicolumn{2}{|c|}{ Top ten active ingredients (medicine items), $n$ (\% of 35175 ) } \\
\hline Venlafaxine & $5222(14.9)$ \\
\hline Escitalopram & $5117(14.6)$ \\
\hline Duloxetine & $3351(9.5)$ \\
\hline Mirtazapine & $2992(8.5)$ \\
\hline Citalopram & $2919(8.3)$ \\
\hline Fluoxetine & $2433(6.0)$ \\
\hline Bupropion & $2153(6.1)$ \\
\hline Sertraline & $2137(6.1)$ \\
\hline Amitriptyline & $2105(6.0)$ \\
\hline Trazodone & $1834(5.2)$ \\
\hline \multicolumn{2}{|c|}{ Antidepressant MPR, $n$ (\% of 35175 ) } \\
\hline$>0-<80$ & $12490(35.5)$ \\
\hline$\geq 80-\leq 110$ & $17435(49.6)$ \\
\hline$>110$ & $5250(14.9)$ \\
\hline
\end{tabular}

\section{Table 2. MPRs of ADs by age group, gender and treatment period}

\begin{tabular}{lllll}
\hline Variable & $n$ & Mean MPR (\%) & 95\% CI & $p$-value \\
\hline Overall & 35175 & 98.2 & $96.6-99.9$ & \\
Age group (years) & & & & 0.0169 \\
$\quad>18-\leq 40$ & 7419 & $102.4^{*}$ & $98.1-106.8$ & \\
$\quad>40-\leq 60$ & 16911 & 98.0 & $95.7-100.4$ & \\
$\quad>60$ & 10845 & $95.6^{*}$ & $93.0-98.3$ & \\
Gender & & & & 0.9200 \\
$\quad$ Male & 9739 & 98.4 & $95.4-101.4$ & \\
$\quad$ Female & 25536 & 98.2 & $96.2-100.1$ & \\
Treatment period (days) & & & & 0.0001 \\
$\quad \leq 30$ & 2769 & 255.4 & $235.7-275.1$ & \\
$\quad>30$ - $\leq 120$ & 9208 & 94.1 & $93.3-94.9$ & \\
$\quad>120$ & 23198 & 81.1 & $80.7-81.5$ & \\
*Significant difference in mean MPR $(p=0.0169)$. & & & & \\
& & & &
\end{tabular}

\section{Changes in PDDs and compliance}

Negative correlations between the initial PDD and PDD changes were found for all ADs $(p=0.0001)$, with $r>-0.5$ for venlafaxine, escitalopram, mirtazapine and amitriptyline. Statistically significant 
differences $(p<0.05 ; d<0.8)$ in the adjusted PDD changes were found between complaint and non-compliant patients on venlafaxine, escitalopram, mirtazapine and amitriptyline therapy (Table 4). The adjusted mean decrease of $6.7 \mathrm{mg}$ (95\% CI $-10.2--3.2)$ in the PDD of venlafaxine in the non-compliant patients was significantly different compared with the mean increase of $1.2 \mathrm{mg}$ ( $95 \% \mathrm{CI}-3.2-5.6)$ in the compliant patients (Table 4). The PDD of mirtazapine also decreased, with an adjusted mean of $0.2 \mathrm{mg}(95 \% \mathrm{CI}-1.2--0.06)$ in the noncompliant patients and $1.2 \mathrm{mg}(95 \% \mathrm{CI} 0.3$ 2.0 ) in the compliant patients (Table 4). The mean adjusted PDD for amitriptyline also decreased, with an adjusted mean of $1.3 \mathrm{mg}$ (95\% CI -2.5 - -0.06) in the non-compliant patients and a $1.5 \mathrm{mg}(95 \% \mathrm{CI}-0.5$ - 3.6) increase in the compliant patients (Table 4). The mean PDD of escitalopram increased more in the compliant patients $(1.7 \mathrm{mg}$; $95 \%$

Table 3. Patient compliance with ADs by age group, gender and active ingredient

\begin{tabular}{|c|c|c|c|}
\hline Variable & Compliant & Non-compliant & $p$-value \\
\hline Overall, $n$ (\% of 35175 ) & $11953(34.0)$ & $23222(66.0)$ & \\
\hline Age group (years), $n(\%)$ & & & 0.0001 \\
\hline$>18-\leq 40$ & $202 / 5419(29.7)$ & $5217 / 5419(70.3)$ & \\
\hline$>40-\leq 60$ & 5 534/16 $911(32.7)$ & $11377 / 16911(67.3)$ & \\
\hline$>60$ & 4 217/10 845 (38.9) & $6628 / 10845(61.1)$ & \\
\hline Gender, $n(\%)$ & & & 0.1342 \\
\hline Male & 3 369/9 739 (34.6) & $6370 / 9739(65.4)$ & \\
\hline Female & $8584 / 25436(33.8)$ & $16852 / 25436(66.3)$ & \\
\hline Top ten active ingredients, $n(\%)$ & & & 0.0001 \\
\hline Venlafaxine & $2026 / 5222(38.8)$ & $3196 / 5222(61.2)$ & \\
\hline Escitalopram & $1796 / 5117(35.1)$ & $3321 / 5117(64.9)$ & \\
\hline Duloxetine & $1295 / 3351(38.7)$ & $2056 / 3351(61.4)$ & \\
\hline Mirtazapine & $862 / 2992(28.8)$ & 2 130/2 $992(71.2)$ & \\
\hline Citalopram & $1032 / 2929(35.4)$ & $1887 / 2919(64.7)$ & \\
\hline Fluoxetine & $763 / 2433(31.4)$ & $1670 / 2433(68.6)$ & \\
\hline Bupropion & $724 / 2153(33.6)$ & $1429 / 2153(66.4)$ & \\
\hline Sertraline & $701 / 2137(32.8)$ & $1436 / 2137(67.2)$ & \\
\hline Amitriptyline & $552 / 2105(26.2)$ & $1553 / 2105(73.8)$ & \\
\hline Trazodone & $602 / 1834(32.8)$ & $1232 / 1834(67.2)$ & \\
\hline
\end{tabular}

Table 4. PDD adjusted for possible change in initial AD dosage in both compliant and non-compliant patients

\begin{tabular}{|c|c|c|c|c|c|c|c|c|c|c|c|}
\hline \multirow[b]{2}{*}{$\begin{array}{l}\text { Top ten active } \\
\text { ingredients }\end{array}$} & \multicolumn{3}{|c|}{ Compliant patients } & \multicolumn{3}{|c|}{ Non-compliant patients } & \multicolumn{2}{|c|}{ Compliant patients } & \multicolumn{3}{|c|}{ Non-compliant patients } \\
\hline & $n$ & $\begin{array}{l}\text { Initial } \\
\text { PDD } \\
(\mathrm{mg})\end{array}$ & $\begin{array}{l}\text { Final } \\
\text { PDD } \\
(\mathrm{mg})\end{array}$ & $n$ & $\begin{array}{l}\text { Initial } \\
\text { PDD } \\
\text { (mg) }\end{array}$ & $\begin{array}{l}\text { Final } \\
\text { PDD } \\
(\mathrm{mg})\end{array}$ & $\begin{array}{l}\text { Adjusted } \\
\text { change in } \\
\text { dosage (mg) }\end{array}$ & $95 \% \mathrm{Cl}$ & $\begin{array}{l}\text { Adjusted } \\
\text { change in } \\
\text { dosage (mg) }\end{array}$ & $95 \% \mathrm{Cl}$ & $p$-value \\
\hline Venlafaxine & 1986 & 136.1 & 137.2 & 3179 & 135.9 & 129.3 & 1.2 & $-3.2-5.6$ & -6.7 & $-10.2--3.2$ & 0.006 \\
\hline Escitalopram & 1796 & 20.7 & 21.9 & 3321 & 19.7 & 20.1 & 1.7 & $1.2-2.2$ & 0.1 & $-0.3-0.5$ & 0.0001 \\
\hline Duloxetine & 1295 & 60.7 & 61.8 & 2056 & 56.3 & 57.3 & 3.9 & $2.0-5.9$ & 1.7 & $0.1-3.2$ & 0.08 \\
\hline Mirtazapine & 862 & 26.3 & 26 & 2126 & 25.1 & 24.7 & 1.2 & $0.3-2.0$ & -0.2 & $-1.2--0.06$ & 0.0007 \\
\hline Citalopram & 1012 & 26.5 & 29.1 & 1871 & 28.7 & 29.1 & 2.4 & $1.5-3.3$ & 1.5 & $0.8-2.2$ & 0.12 \\
\hline Fluoxetine & 731 & 32.9 & 33 & 1654 & 33 & 33.1 & 0.8 & $-0.5-2.1$ & 0.5 & $-0.4-1.4$ & 0.76 \\
\hline Bupropion & 724 & 235 & 242.8 & 1429 & 238.6 & 246.7 & 27.0 & $11.2-42.8$ & 26.8 & $16.5-37.1$ & 0.98 \\
\hline Sertraline & 675 & 78.7 & 82.6 & 1418 & 80.5 & 84.4 & 5.8 & $3.6-8.1$ & 5.7 & $4.1-7.2$ & 0.90 \\
\hline Amitriptyline & 522 & 43.2 & 43.3 & 1553 & 40.6 & 37.9 & 1.5 & $-0.5-3.6$ & -1.3 & $-2.5--0.06$ & 0.02 \\
\hline Trazodone & 602 & 274.6 & 284.2 & 1232 & 390.7 & 362.5 & -13.9 & $-34.8-7.0$ & 4.2 & $-10.4-18.8$ & 0.16 \\
\hline
\end{tabular}


and inappropriate discontinuation evoke a stress response that may adversely affect long-term outcomes. ${ }^{[21,22]}$

It could also be argued that males would be more likely to discontinue their $\mathrm{AD}$ medication voluntarily, owing to a stronger negative bias associated with the psychological stigma of the illness. However, we did not observe any significant association between compliance and gender. Two earlier studies have also noted that the gender of ambulatory patients treated with $\mathrm{AD}$ is a weak predictor of non-compliance. ${ }^{[18,37]}$

Our study also reveals that elderly patients ( $>60$ years) may be more compliant than younger populations taking ADs. In fact, elderly patients demonstrate reduced dropout ratios and are more likely to comply with their medication, and in some cases respond better to treatment, than younger patients. ${ }^{[38]}$ Younger patients have a stronger negative bias towards issues such as weight gain, sexual dysfunction and dissatisfaction with the physician. ${ }^{[39,40]}$

We also demonstrated that the treatment period has a definite influence on the MPR and patient compliance. We found that patients were prescribed an oversupply of $\mathrm{AD}$ during the first month of treatment. This is an interesting observation, especially since giving excessive medication may constitute a risk in patients with suicidal ideation. However, issues of dosage instability, side-effects and changing the regimen or dosage may explain this observation. Moreover, hospitalisation and co-prescription of medicines may also occur. These findings should be considered when calculating the MPR as a measure of patient compliance, taking into account that patients on $\mathrm{AD}$ treatment first need to be stabilised on the correct $\mathrm{AD}$ and dose. However, it is of great concern that patients became gradually less compliant in the latter part of the 4-month treatment period.

The serotonin re-uptake inhibitors (SSRIs), represented here by escitalopram, citalopram, fluoxetine and sertraline, are first-line treatments for MDD because of improved safety and reduced cost, ${ }^{[10]}$ and are the most frequently dispensed class of ADs for this disorder. ${ }^{[41]}$ Furthermore, in the SA private health sector they have compliance rates of between $32.8 \%$ and $34 \%$ (this study), which is slightly higher than the $25.5 \%$ reported elsewhere. ${ }^{[42]}$ The low compliance with SSRIs in this study population is a noteworthy observation. We found compliance ratios for venlafaxine and duloxetine to be significantly better $(p<0.001)(38.8 \%$ and $38.7 \%)$ than that for amitriptyline (26.2\%). Amitriptyline was found to have the worst compliance, perhaps because of its greater side-effect burden. ${ }^{[43-45]}$ A negative correlation was found between the initial PDD and the change in PDD, implying that the higher the initial PDD the smaller the change in PDD, particularly for venlafaxine, escitalopram, mirtazapine and amitriptyline. A higher initial PDD was also associated with better compliance with $\mathrm{AD}$ treatment. This finding is supported in the literature, as several studies have found that MDD is commonly treated with inadequate doses of ADs. ${ }^{[46-48]}$ Furthermore, a study by Marcus et al. ${ }^{[49]}$ found that a lower initial dose of $\mathrm{AD}$ was associated with subsequent switching to another $\mathrm{AD}$ or to an entirely new class of $\mathrm{AD}$, suggesting that an inadequate dose at the start of treatment may contribute to a suboptimal response to initial $\mathrm{AD}$ treatment and therefore increase the possibility of $\mathrm{AD}$ switching and relapse.

\section{Conclusion}

We established that compliance with $\mathrm{AD}$ treatment remains a major obstacle in the treatment of MDD in a middle-income developing country like SA. These findings are worrying, as such non-compliance may have significant negative effects not only on the long-term treatment outcome of MDD but also that of comorbid disorders. Some of these aspects are currently under study by our research group. We found that only a third of patients suffering from MDD are compliant with their $\mathrm{AD}$ treatment, with newer-generation $\mathrm{ADs}$ (particularly serotonin noradrenaline reuptake inhibitors (SNRIs)) performing better. We also verified that data from medicine claims may be used as a measure of patient compliance in the clinical setting. Furthermore, the treatment period has a statistically significant effect on the MPR when used as a measure of compliance.

Conflict of interest. BHH has participated in speakers/advisory boards and received honoraria from Organon, Pfizer and Servier, and has received research funding from Lundbeck and Servier. Except for income from the primary employer and research funding to BHH from the SA Medical Research Council, and the exceptions noted earlier, no financial support or compensation has been received from any individual or corporate entity over the past 3 years for research or professional services, and there are no personal financial holdings that could be perceived as constituting a potential conflict of interest.

Acknowledgements. We thank Dr Suria Ellis from Statistical Consultation Services, North-West University, Potchefstroom Campus, for statistical support, and Anne-Marie Bekker for administrative support regarding the database. The authors thank North-West University, the National Research Foundation and the South African Medical Research Council for financial support.

\section{References}

1. Tomlinson M, Grimsrud AT, Stein DJ, et al. The epidemiology of major depression in South Africa: Results from the South African stress and health study. S Afr Med J 2009;99(5):367-373.

2. Kessler RC, Chiu WT, Demler O, et al. Prevalence, severity, and comorbidity of 12-month DSM-IV disorders in the National Comorbidity Survey Replication. Arch Gen Psychiatry 2005;62(6):617-627. [http://dx.doi.org/10.1001/archpsyc.62.6.617]

3. Alonso J, Angermeyer MC, Bernert S, et al. Disability and quality of life impact of mental disorders in Europe: Results from the European Study of the Epidemiology of Mental Disorders (ESEMeD) project. Acta Physiol Scand Suppl 2004;109(Suppl S420):38-46. [http://dx.doi.org/10.1111/j.1600-0047.2004.00329.x]

4. Goodwin FK, Jamison KR. Suicide in Manic-depressive Illness. New York: Oxford University Pres, 1990:227-244.

5. Andlin-Sobocki P. Jonsson B, Wittchen HU, et al. Cost of disorders of the brain in Europe. Eur I Neuro 2005;12 (Suppl 1):1-27. [http://dx.doi.org/10.1111/j.1468-1331.2005.01202.x]

2011. hup 6. Ne numbers count: Mental disorders in America. 2011. http: $/ /$ www.nimh.nih.gov/health/publications/the-numbers-count-mentaldisorders-in-america/index
shtml\#Intro (accessed 15 June 2012). shtml\#Intro (accessed 15 June 2012).

7. Lund C, Myer L, Stein DJ, et al. Mental illness and lost income among adult South Africans. So Psychiatry Psychiatr Epidemiol 2013;48(5):845-851. [http://dx.doi.org/10.1007/s00127-012-0587-5] 8. Osterberg L, Blaschke T. Adherence to medication. N Engl J Med 2005;353(5):487-497. [http://dx.doi org/10.1056/NEJMra050100]

. National Institute for Health and Clinical Excellence. Depression: The treatment and managemen of depression in adults. Partial update of NICE clinical guideline 2009. http://www.nice.org.uk/ nicemedia/pdf/CG90NICEguideline.pdf (accessed 2 May 2013).

10. Keller MB, Hirschfeld RM, Demyttenaere K, et al. Optimizing outcomes in depression: Focus on antidepressant compliance. Int Clin Psychopharmacol 2002;17(6):265-271.

11. Akerblad AC, Bengtsson F, von Knorring L, et al. Response, remission and relapse in relation to adherence in primary care treatment of depression: A 2-year outcome study. Int Clin Psychopharmacol
2006;21(2):117-124.

12. Akerblad AC, Bengtsson F, Holgersson M, et al. Identification of primary care patients at risk of nonadherence to antidepressant treatment. Patient Prefer Adherence 2008;2:379-386.

13. Geddes JR, Carney SM, Davies C, et al. Relapse prevention with antidepressant drug treatment in Geddes JR, Carney SM, Davies C, et al. Relapse prevention with antidepressant drug treatment in
depressive disorders: A systematic review. Lancet 2003;361(9358):653-661. [http://dx.doi.org/10.1016/ depressive disorders: A sy

14. Serna MC, Cruz I, Real J, et al. Duration and adherence of antidepressant treatment (2003 to 2007) based on prescription database. Eur Psychiatry 2010;25(4):206-213. [http://dx.doi.org/10.1016/j. eurpsy.2009.07.012]

15. Demyttenaere K. Compliance during treatment with antidepressants. J Affect Disord 1997;43(1):27-39. [http://dx.doi.org/10.1016/S0165-0327(96)00095-X]

16. Cramer JA. Optimizing long-term patient compliance. Neurology 1995;45(2 Suppl 1):S25-S28.

17. Hotopf M, Hardy R, Lewis G. Discontinuation rates of SSRIs and tricyclic antidepressants: A meta-analysis and investigation of heterogeneity. Br J Psychiatry 1997;170:120-127. [http://dx.doi. org/10.1192/bjp.170.2.120]

18. Lin EH, von Korff M, Katon W, et al. The role of the primary care physician in patients' adherence to antidepressant therapy. Med Care 1995;33(1):67-74. [http://dx.doi.org/10.1097/00005650-199501000-00006]

19. Robinson $P$, Bush T, von Korff $M$, et al. Primary care physician use of cognitive behavioral techniques Robinson P, Bush T, von Korff M, et al. Primary care phy
with depressed patients. J Fam Pract 1995;40(4):352-357.

20. Frank E, Perel JM, Mallinger AG, et al. Relationship of pharmacologic compliance to long-term prophylaxis in recurrent depression. Psychopharmacol Bull 1992;28(3):231-235.

21. Harvey BH, McEwen BS, Stein DJ. Neurobiology of antidepressant withdrawal: Implications for the longitudinal outcome of depression. Biol Psychiatry 2003;54(10):1105-1117. [http://dx.doi. org/10.1016/S0006-3223(03)00528-6]

2. Harvey BH. Adaptive plasticity during stress and depression and the role of glutamate-nitric oxide pathways. S Afr Psychiatry Rev 2006;9:132-139. http://www.ajol.info/index.php/ajpsy/article/ viewFile/30214/22831 (accessed 27 December 2014)

23. MIMS: Monthly Index of Medical Specialities 2012;51(2):13-28 
24. World Health Organization. ICD-10 Version: 2010. http://apps.who.int/classifications/icd10/ browse/2010/en (accessed 23 November 2012).

25. Cramer JA, Benedict A, Muszbek N, et al. The significance of compliance and persistence in the treatment of diabetes, hypertension and dyslipidaemia: A review. Int J Clin Pract 2008:62(1):76-87. [http://dx.doi.org/10.1111/j.1742-1241.2007.01630.x]

26. Weycker D, Macarios D, Edelsberg J, et al. Compliance with osteoporosis drug therapy and risk of fracture. Osteoporos Int 2007;18(3):271-277. [http://dx.doi.org/10.1007/s00198-006-0230-y]

27. Weiden PJ, Kozma C, Grogg A, et al. Partial compliance and risk of rehospitalization among Californi Medicaid patients with schizophrenia. Psychiatr Serv 2004;55(8):886-891. [http://dx.doi.org/10.1176 appi.ps.55.8.886]

28. Paterson DL, Swindells S, Mohr J, et al. Adherence to protease inhibitor therapy and outcomes in patients with HIV infection. Ann Intern Med 2000;133(1):21-30. [http://dx.doi.org/10.7326/00034819-133-1-200007040-00004

29. Steiner JF, Prochazka AV. The assessment of refill compliance using pharmacy records: Methods, validity, and applications. J Clin Epidemiol 1997;50(1):105-116. [http://dx.doi.org/10.1016/S08954356(96)00268-5].

30. Steyn HS. Manual for the Determination of Effect Size Indices and Practical Significance. Potchefstroom North-West University. http://www.nwu.ac.za/content/statcs-effect-size (accessed 25 September 2012).

31. Bambauer KZ, Adams AS, Zhang F, et al. Physician alerts to increase antidepressant adherence: Fax or fiction? Arch Intern Med 2006;166(5):498-504. [http://dx.doi.org/10.1001/archinte.166.5.498]

32. Demyttenaere K, Enzlin P, Dewe W, et al. Compliance with antidepressants in a primary care setting. 1 : Beyond lack of efficacy and adverse events. J Clin Psychiatry 2001;62(Suppl 22):30-33.

33. Pampallona S, Bollini P, Tibaldi G, et al. Combined pharmacotherapy and psychological treatment for depression: A systematic review. Arch Gen Psychiatry 2004;61(7):714-719. [http://dx.doi.org/10.1001/ archpsyc.61.7.714]

4. Kessler RC. Epidemiology of women and depression. J Affect Disord 2003;74(1):5-13. [http://dx.doi org/10.1016/S0165-0327(02)00426-3]

35. Harvey BH, Hamer M, Louw R, et al. Metabolic and glutathione redox markers associated with brainderived neurotrophic factor in depressed African men and women: Evidence for counterregulation? Neuropsychobiology 2013;67(1):33-40. [http://dx.doi.org/10.1159/000343501]

36. Hankin BL, Abramson LY. Development of gender differences in depression: An elaborated cognitive vulnerability-transactional stress theory. Psychol Bull 2001;127(6):773-796. [http://dx.doi org/10.1037/0033-2909.127.6.773]

37. Simon GE, von Korff M, Wagner EH, et al. Patterns of antidepressant use in community practice. Gen Hosp Psychiatry 1993;15(6):399-408.
38. Birrer RB, Vemuri SP. Depression in later life: A diagnostic and therapeutic challenge. Am Fam Physician 2004;69(10):2375-2382

39. Akincigil A, Bowblis JR, Levin C, et al. Adherence to antidepressant treatment among privately insured Akincigil A, Bowblis $\mathrm{R}$, Levin C, et al. Adherence to antidepressant treatment among privately insured
patients diagnosed with depression. Med Care 2007;45(4):363-369. [http://dx.doi.org/10.1097/01. patients diagnosed with
mlr.0000254574.23418.f6]

40. Tamburrino MB, Nagel RW, Chahal MK, et al. Antidepressant medication adherence: A study of primary care patients. J Clin Psychiatry 2009;11(5):205-211. [http://dx.doi.org/10.4088\%2FPCC.08m00694]

41. Gelenberg AJ, Freeman MP, Markowitz JC, et al. American Psychiatric Association. Practice Guideline for the Treatment of Patients with Major Depressive Disorder. 3rd ed. 2010. http://www. psychiatryonline.com/pracGuide/pracGuideTopic_7.aspx (accessed 17 July 2013).

42. Liu X, Chen Y, Faries DE. Adherence and persistence with branded antidepressants and generic SSRIs among managed care patients with major depressive disorder. Clinicoecon Outcomes Res 2011;2011(3):63-72. [http://dx.doi.org/10.2147\%2FCEOR.S17846]

43. Baldwin DS. Unmet needs in the pharmacological management of depression. Hum Psychopharmacol Clin Exp 2001;16(S2):S93-S99. [http://dx.doi.org/10.1002/hup.337]

44. Hirschfeld RM. Antidepressants in long-term therapy: A review of tricyclic antidepressants and selective serotonin reuptake inhibitors. Acta Psychiatr Scand Suppl 2000;101(S403):35-38. [http:// dx.doi.org/10.1111/j.1600-0447.2000.tb10946.x]

45. Masand PS. Tolerability and adherence issues in antidepressant therapy. Clin Ther 2003;25(8):22892304. [http://dx.doi.org/10.1016/S0149-2918(03)80220-5]

46. Dew RE, Kramer SI, McCall WV. Adequacy of antidepressant treatment by psychiatric residents: The antidepressant treatment history form as a possible assessment tool. Acad Psychiatry 2005;29(3):283288. [http://dx.doi.org/10.1176/appi.ap.29.3.283]

47. Mulsant BH, Haskett RF, Prudic J, et al. Low use of neuroleptic drugs in the treatment of psychotic major depression. Am J Psychiatry 1997;154(4):559-561. [http://ajp.psychiatryonline.org/doi/ pdfplus/10.1176/ajp.154.4.559]

48. Shasha M, Lyons JS, O’Mahoney MT, Rosenberg A, Miller SI, Howard KI. Serotonin reuptake inhibitors and the adequacy of antidepressant treatment. Int J Psychiatry Med 1997;27(2):83-92. [http://dx.doi. org/10.2190/YVBE-MXAF-Q09Q-Y02Q]

49. Marcus SC, Hassan M, Olfson M. Antidepressant switching among adherent patients treated for depression. Psychiatr Serv 2009;60(5):617-623. [http://dx.doi.org/10.1176/appi.ps.60.5.617]

Accepted 22 October 2014 